\title{
Measurement of Intracellular Fluorescence of Human Monocytes Relative to Oxidative Metabolism
}

\author{
J. Paul Robinson, Leon H. Bruner, Carl-F. Bassoe, Jerry L. Hudson, \\ Peter A. Ward, and Sem H. Phan \\ Department of Pathology, University of Michigan, Ann Arbor (J.P.R., L.H.B., J.L.H., P.A.W., \\ S.H.P.), and Department of Pathology, University of Bergen, Bergen, Norway (C.-F.B.)
}

\begin{abstract}
Human monocytes (MN) produce $\mathrm{O}_{2}^{-}$and $\mathrm{H}_{2} \mathrm{O}_{2}$ when stimulated by agonists. Dichlorofluorescin diacetate (DCFH-DA) has been used as a substrate for measuring intracellular oxidant production in neutrophils. DCFH-DA is hydrolyzed by esterases to dichlorofluorescin (DCFH), which is trapped within the cell. This nonfluorescent molecule is then oxidized to fluorescent dichlorofluorescin (DCF) by action of cellular oxidants. DCFH-DA can not be appreciably oxidized to a fluorescent state without prior hydrolysis. We have examined the utility of DCFH-DA for the assessment of monocyte oxidative responses. The levels of intracellular fluorescence measured by flow cytometry were considerably less than expected from reported levels of $\mathrm{O}_{2}{ }^{-}$-production or chemiluminescence assays. Compared with neutrophils, monocytes produced minimal increases in DCF fluorescence after stimulation with phorbol myristate acetate as measured by flow cytometry, but both cell types showed increases in fluorescence when bulk cell suspensions were measured by spectrofluorometry. To determine the intracellular location of the DCFH, bulk fluorescence measurements were made on both whole and sonicated cell preparations. When intact mononuclear cells were preloaded with DCFH-DA, then sonicated and oxidized with added excess $\mathrm{H}_{2} \mathrm{O}_{2}$, the increase in fluorescence was only $30 \%$ of the fiuorescence of mononuclear cell sonicates to which DCFH-DA was added and oxidized in a similar manner. These results suggest that a portion of the DCFH-DA incorporated by intact cells, is not susceptible to oxidation by the added $\mathrm{H}_{2} \mathrm{O}_{2}$. Addition of $\mathrm{NaOH}$ to induce hydrolysis of any residual DCFH-DA in the sonicates of DCFH-DA-loaded intact mononuclear cells resulted in a further increase in fluorescence upon addition of $\mathrm{H}_{2} \mathrm{O}_{2}$, suggesting that a significant portion of the DCFH-DA was not hydrolyzed despite ample uptake of this dye by these cells. In contrast, no further increase in fluorescence was observed in sonicates of DCFH-DA-loaded intact neutrophils, suggesting complete hydrolysis of all incorporated DCFH-DA to DCFH. When monocytes were allowed to phagocytose DCFH-DA-loaded Staphylococcus aureus, Intracellular fluorescence was measurable by flow cytometry, indicating intracellular oxidation of the fluorochromes. We therefore propose that in monocytes the mechanism of intracellular processing of these fluorochromes differs from that in neutrophils owing to differences in intracellular localization of fluorochromes, site of oxidant production, and/or accessibility of the DCFH-DA to esterolysis.
\end{abstract}

Key words: neutrophil, dichlorofluorescin, $\mathrm{H}_{2} \mathrm{O}_{2}$

\section{INTRODUCTION}

The use of intracellular fluorochromes, particularly dichlorofluorescin diacetate (DCFH-DA), to monitor the production of oxidants by neutrophils has become a valuable research tool $[2,3,6]$. An intracellular measure of oxidant production would enable further understanding of the differences in oxidative metabolism between monocytes and neutrophils. We have used DCFH-DA in an attempt to measure the generation of intracellular oxidants in human monocytes but have been unable to measure significant quantities of fluorescence by flow cytometry. Previous workers, using bulk measurement techniques, have demonstrated that appropriately stimu- lated human monocytes produce $\mathrm{O}_{2}-[7]$, chemilumines cence (CL) $[12,14]$ and $\mathrm{H}_{2} \mathrm{O}_{2}$ [13] in almost the sam quantities as neutrophils, albeit with different kinetics.

Current methods measure primarily extracellular pro duction of $\mathrm{H}_{2} \mathrm{O}_{2}$ or $\mathrm{O}_{2}$ - in phagocytes [1]. It is not clea

Received July 27, 1987; accepted October 27, 1987.

Presented in abstract form at the 6th International Immunology Con gress, Toronto, July, 1986.

Reprint requests: J. Paul Robinson, Department of Pathology, Univer sity of Michigan Hospitals, Med Sci. I M2246-0602, 1301 Catherine Ann Arbor, MI 48109-0602. 
whether CL measurements are related to intra- or extracellular events or what oxidant is being measured. On the other hand, the measurement of DCF fluorescence by flow cytometry is mostly intracellular.

Recently, Bender and colleagues [4] indicated that they could measure intracellular oxidant production in human monocytes, although in that study it is unclear how much oxidant is actually produced by these cells. This report suggests that DCF-associated fluorescence can only be detected in human monocytes after stimulation with particulate but not soluble activators.

\section{MATERIALS AND METHODS \\ Buffers and Lysing Solution}

Phosphate-buffered saline (PBS) contained $0.147 \mathrm{M}$ $\mathrm{NaCl}, 4.1 \mathrm{mM} \mathrm{Na}_{2} \mathrm{HPO}_{4} \cdot 7 \mathrm{H}_{2} \mathrm{O}, 2.3 \mathrm{mM} \mathrm{NaH} \mathrm{PO}_{4}, 15$ $\mathrm{mM} \mathrm{NaNO}$, pH 7.4 PBS-gel is PBS which also contained $2 \mathrm{mM}$ EDTA, $10 \mathrm{mM}$ glucose, and $1 \%$ gelatin (Difco Laboratories, Detroit, MI) and was used for all cell incubations. Lysing solution consisted of $0.15 \mathrm{M}$ $\mathrm{NH}_{4} \mathrm{Cl}, 10 \mathrm{mM} \mathrm{NaHCO}, 10 \mathrm{mM}$ ethylenediamine tetraacetic acid (EDTA) at pH 7.4.

\section{Reagents}

2',7'-Dichlorofluorescin diacetate (DCFH-DA) (Eastman Kodak Co, Rochester, NY) was dissolved in absolute ethanol at a concentration of $5 \mathrm{mM}$ and kept at $4^{\circ} \mathrm{C}$ for up to 4 wk. 5',6'-Carboxy-2', 7'-dichlorofluorescein diacetate (CF-DA) (Molecular Probes, Junction City, OR) was dissolved under the same conditions. Phorbol myristate acetate (PMA) (Consolidated Midland, Brewster, NJ) was dissolved in dimethyl sulfoxide (DMSO) as a stock solution of $1 \mu \mathrm{M}(2 \mathrm{mg} / \mathrm{ml})$ and stored in $20-\mu \mathrm{l}$ aliquots at $-20^{\circ} \mathrm{C}$.

\section{Preparation of Cells}

Human blood was drawn into a syringe containing preservative-free heparin (5 IU/ml blood) (Elkins-Sinn Inc, Cherry Hill, NJ). Blood was diluted 1:2 with PBS and layered onto Lymphocyte Separation Medium (LSM) (Bionetics Laboratory Products, Kensington, MD) at a ratio of $2 \mathrm{ml}$ diluted blood per $1 \mathrm{ml} \mathrm{LSM}$. Blood was centrifuged at $600 \mathrm{~g}$ for $25 \mathrm{~min}$ at $25^{\circ} \mathrm{C}$ in a Beckman bench centrifuge (model TJ-6) according to the methods of Boyum [5]. The interface containing the mononuclear cells was removed and diluted 1:2 with PBS in a 50-ml sterile polyethelene tube (Corning Glass Works, Corning, NY) followed by three washes to remove excess LSM and platelets. Cells were resuspended at a $1 \times 10^{7} /$ $\mathrm{ml}$ in PBS-gel.

\section{Fluorescence Assay}

Flow cytometry. Cell populations $\left(1 \times 10^{6} / \mathrm{ml}\right)$ were incubated with fluorochromes $(5 \mu \mathrm{M})$ for $15 \mathrm{~min}$ at $37^{\circ} \mathrm{C}$. These loaded cells were then placed into a temperature-controlled chamber in the flow cytometer (EPICS 753, EPICS Division, Coulter Electronics, Hialeah, FL). All measurements were performed using an argon ion laser emitting $300 \mathrm{mw}$ at $488 \mathrm{~nm}$ with emission measured using 525-nm band-pass filters. At zero time, PMA (100 $\mathrm{ng} / \mathrm{ml}$, final concentration) was added, and the samples were constantly mixed while running through the cytometer. Temperature was maintained at $37^{\circ} \mathrm{C}$ throughout. Signals were collected as ungated list mode data. Parameters collected included forward angle light scatter (FLS), $90^{\circ}$ light scatter (90LS), green fluorescence (GFL), and time. A typical kinetics experiment included the analysis of 250,000-750,000 individual cells over $15 \mathrm{~min}$.

Spectrofluorometry. All bulk fluorescence measurements were performed on a Varian SF-330 spectrofluorometer (Varian Associates Inc, Palto Alto, CA) using 3ml quartz curvettes. Temperature was maintained at $37^{\circ} \mathrm{C}$ with a heated sample compartment. All measurements were made with the instrument excitation wavelength set at $488 \mathrm{~nm}$ and emission wavelength at $530 \mathrm{~nm}$, and both with 10-nm slit widths.

Sonication of cells was performed with a sonicator model W255R (Heat Systems-Ultrasonics, Inc., Plainview, NY). Cells $\left(1 \times 10^{6} / \mathrm{ml}\right.$ in 5 -ml volumes) were sonicated on ice three times each with 12-sec bursts at 30 W. Microscopic analysis showed complete cell disintegration. Additions of $\mathrm{H}_{2} \mathrm{O}_{2}$ and $\mathrm{NaOH}$, where indicated in the text, refer to final concentrations unless otherwise stated.

\section{RESULTS \\ Flow Cytometric Measurement of DCFH-DA Fluorescence in Mononuclear Cells}

To assess the intracellular fluorescence of DCFH-DAloaded cells, mononuclear cells $\left(1 \times 10^{6} / \mathrm{ml}\right)$ were loaded with DCFH-DA $(5 \mu \mathrm{M})$ for $15 \mathrm{~min}$ at $37^{\circ} \mathrm{C}$ and run on the flow cytometer. Using light-scatter gating techniques the fluorescence of each cell population was monitored for $15 \mathrm{~min}$. Two populations of cells were identified by light scatter. Lymphocytes (low FLS and 90LS) exhibited a basal fluorescence with no increase in the mean fluorescence channel during stimulation with PMA over 15 min. The second population consisted of monocytes and showed variable fluorescence. The majority of cells (>90\%) showed almost no increase in fluorescence (mean channel No. from 25.5 to 51.85) after stimulation with PMA (0.1-100 ng/ml). A very small percentage of cells $(<5 \%)$ became slightly fluorescent during the 15 min measurement (mean channel No. 102.5). This responsive population of cells may represent neutrophils which have gated within the gates set for the monocytes. These cells may be less dense than normal neutrophils and were collected in the interface with mononuclear cells. 
Measurements were made with both density-gradientseparated cells (LSM) and whole blood samples in which erythrocytes had been lysed, to determine whether separation procedures altered the ability of mononuclear cells to utilize the DCFH-DA. In both cases mononuclear cells were gated by forward and $90^{\circ}$ light scatter. Cell preparations were measured kinetically for up to $20 \mathrm{~min}$ while maintaining the cell suspension at $37^{\circ} \mathrm{C}$. All samples were mixed continuously using the standard sample mixer on the EPIC 753 flow cytometer. No, or very low, fluorescence was measured in either monocyte or lymphocyte populations despite consistently observing dose-dependent increases in fluorescence by neutrophils (mean channel No. from 17.0 to 221) in the same samples (Fig. 1). Thus, accurate and reliable measurement of intracellular monocyte oxidative metabolism using the DCFH-DA fluorochrome under these conditions was not possible by
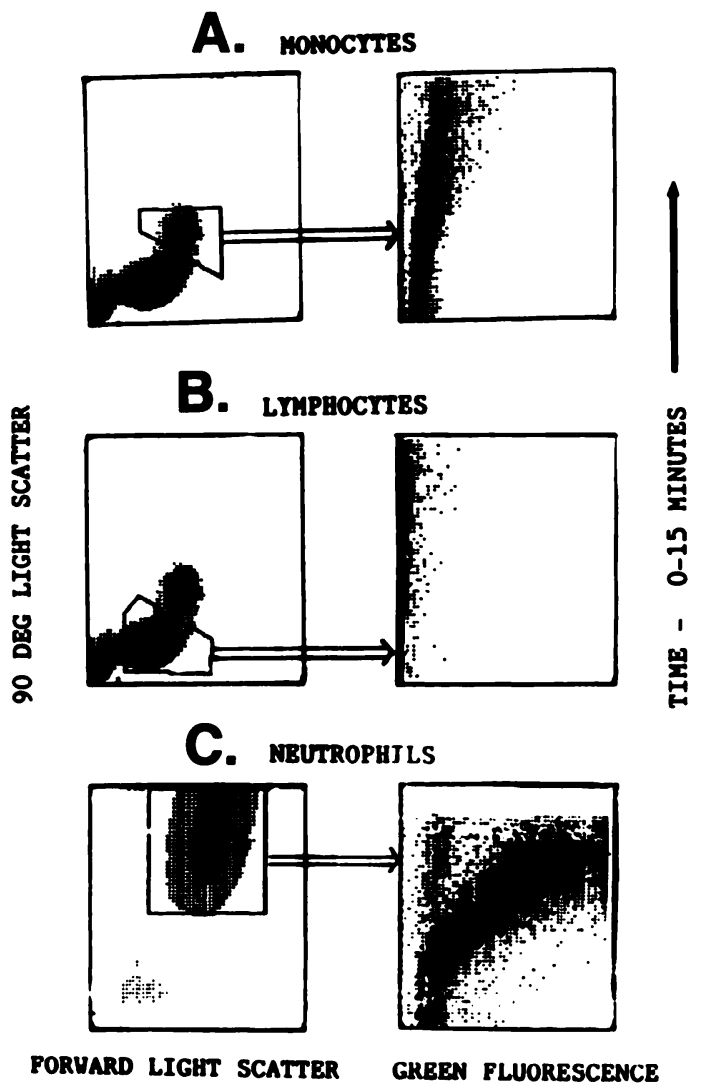

Fig. 1. Flow cytometric histograms showing forward-angle light scatter versus $90^{\circ}$ light scatter on the left of the figure and, on the right, the resultant green fluorescence (GFL) from the gated population plotted as GFL vereus time $(0-15 \mathrm{~min})$. All cell preparations were stimulated at zero time with PMA (100 $\mathrm{ng} / \mathrm{ml})$. A shows the gated monocytes from Hypaque-separated mononuclear cells. Almost no increase in fluorescence was observed over 15 minutes. B shows the same for the gated lymphocyte population, and C shows the increase in GFL observed with PMA stimulation of neutrophils. In the neutrophils, a small nonresponsive population was observed and consisted of less than $10 \%$ of the neutrophils. flow cytometry. The following studies were undertaken to investigate the apparent discrepancy between flow cytometric and bulk suspension assays.

\section{Spectrofluorometric Measurement of DCFH-DA and CF-DA Fluorochromes}

The use of DCFH-DA as an intracellular probe for intracellular oxidation products is based upon the intacellular hydrolysis of DCFH-DA to form DCFH by esterase(s), which is then susceptible to oxidation to form the fluorescent production DCF. Thus, the lack of fluorescence in the flow cytometric assay could be the result of poor hydrolysis of DCFH-DA and/or oxidation of DCFH. First, to examine this esterolytic step in monocytes and neutrophils, two fluorochromes which are hydrolyzed by similar esterases were used. Hydrolysis of DCFH-DA forms a nonfluorescent molecule, DCFH. However, hydrolysis of nonfluorescent CF-DA results in the direct formation of a fluorescent product, carboxyfluorescein (CF). CF-DA is therefore a good substrate for the direct measurement of the intracellular esterolytic capacity. DCFH-DA was added to mononuclear cells (containing $1 \times 10^{6}$ monocytes) or neutrophils $\left(1 \times 10^{6}\right)$ for $15 \mathrm{~min}$ at $37^{\circ} \mathrm{C}$. Spectrofluorometric tracing indicated no or minimal increase in fluorescence with mononuclear cells or neutrophils in the absence of added stimulus. CF-DA addition to the same number of mononuclear cells or neutrophils caused a rapid increase in the fluorescence within seconds of addition which continued for at least 30 min, suggesting that the CF-DA was being hydrolyzed rapidly as soon as it entered the cells (fluorescence after $15 \mathrm{~min}$ for mononuclear cells $70 \% \pm 5 \%$ of final fluorescence, and for neutrophils fluorescence was $63 \% \pm$ $7 \%$ of final fluorescence, $\mathrm{N}=2)$. Addition of base (0.1 $\mathrm{N} \mathrm{NaOH}$ ) to the cell suspensions followed by neutralization back to $\mathrm{pH} 7.4$ failed to increase the fluorescence further, suggesting total hydrolysis of intracellular CFDA in both cell types. When DCFH-DA-loaded mononuclear cells or neutrophils were stimulated with PMA $(100 \mathrm{ng} / \mathrm{ml})$, an increase in fluorescence of the cell suspension was observed for both cell types (Fig. 2), suggesting the hydrolysis of the DCFH-DA to DCFH and subsequent oxidation to DCF. In this type of bulk suspension assay, however, the location of the fluorescent product is uncertain, but subsequent data showed that the bulk of the fluorescence was in the cell supernates. This suggests that the flow cytometric assay failed to show significant fluorescence because of a lack of intracellular hydrolysis of DCFH-DA and/or intracellular oxidation of DCFH. The CF-DA data, however, seems to indicate adequate hydrolytic mechanisms for that probe, although DCFH-DA may either partition differently inside the cell, or be less susceptible to hydrolysis by the same esterase, or both. These possibilities were then explored further in the following experiments. 


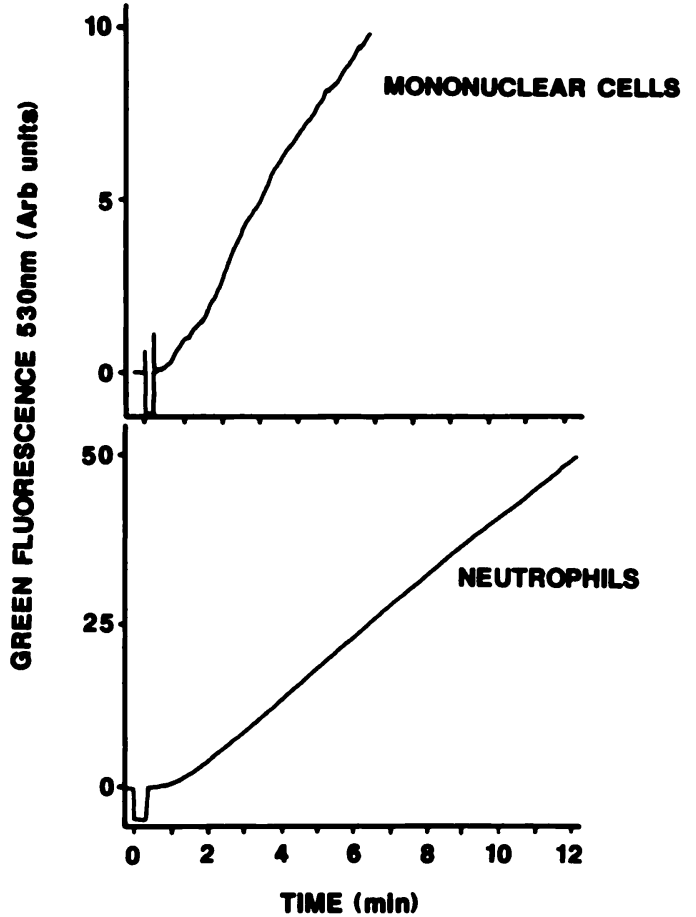

Fig. 2. Spectrofluorometric tracings showing the increasing fuorescence of DCFH-DA loaded (but unwashed) monocytes (top) and neutrophils (bottom) after stimulation with PMA (100 $\mathrm{ng} / \mathrm{ml})$. Green fluorescence was measured with excltation at $488 \mathrm{~nm}$ and emiseion at $530 \mathrm{~nm}$ at $37^{\circ} \mathrm{C}$. Both mononuclear cells and neutrophils demonstrated increasing fluorescence after stimulation.

\section{Efficiency of Mononuclear Cells' Hydrolytic Mechanisms}

To establish whether there was residual intracellular DCFH-DA which had not been converted to DCFH, intact mononuclear cells and neutrophils were loaded with $5 \mu \mathrm{M}$ DCFH-DA for $15 \mathrm{~min}$ at $37^{\circ} \mathrm{C}$, washed, and sonicated. $\mathrm{NaOH}(0.1 \mathrm{~N}$, final concentration) was added to the sonicates for $3 \mathrm{~min}$ ( $\mathrm{pH} \mathrm{10.4)} \mathrm{(to} \mathrm{hydrolyze} \mathrm{any}$ DCFH-DA available), and the fluorescence was measured spectrophotometrically after readjusting to $\mathrm{pH} 7.4$, before and after addition of $\mathrm{H}_{2} \mathrm{O}_{2}(1 \mu \mathrm{M}$ final concentration). $\mathrm{H}_{2} \mathrm{O}_{2}$ added to DCFH-DA alone did not result in any fluorescent products. In the absence of added $\mathrm{H}_{2} \mathrm{O}_{2}$ there was no significant difference in the fluorescence of cell sonicates before or after the treatment with $\mathrm{NaOH}$. Upon addition of $\mathrm{H}_{2} \mathrm{O}_{2}$, the fluorescence of mononuclear cell sonicates increased significantly, with the increase being approximately $100 \%$ greater after base hydrolysis than that without base hydrolysis. A smaller difference (approximately 25\%) was seen in neutrophil sonicates between base-hydrolyzed versus nonhydrolyzed preparations. The final fluorescence after both base hydrolysis and $\mathrm{H}_{2} \mathrm{O}_{2}$ addition was greater in mononuclear cells than in neutrophils, suggesting equal or greater DCFH-DA uptake in mononuclear cells. These data suggest less efficient intracellular hydrolysis of DCFH-DA in mononuclear cells relative to neutrophils despite equal if not greater uptake of DCFH-DA in mononuclear cells.

This difference between the two cell types is more apparent when the effect of base hydrolysis was analyzed in cell sonicates to which DCFH-DA was added (Table 1). In this experiment, cells were sonicated first, and DCFH-DA $(5 \mu \mathrm{M})$ was added to the sonicates and incubated at $37^{\circ} \mathrm{C}$ for $15 \mathrm{~min}$. Aliquots were then taken which were hydrolyzed with $0.1 \mathrm{~N} \mathrm{NaOH}$ and reneutralized as described above. Upon addition of $1 \mu \mathrm{M} \mathrm{H}_{2} \mathrm{O}_{2}$ the increase in fluorescence in mononuclear cells was approximately $300 \%$ greater in base-hydrolyzed versus nonhydrolyzed sonicates. In contrast, neutrophil sonicates showed no significant difference in $\mathrm{H}_{2} \mathrm{O}_{2}$-induced fluorescence increase as a result of base hydrolysis (Table 1 ). The same experiments were performed with CF-DA, using mononuclear cells, and these experiments confirmed that approximately $70 \%$ of the fluorochrome was hydrolyzed in both sonicates and whole cells (Table 2). These results demonstrate a markedly less efficient system for DCFH-DA hydrolysis in mononuclear cells than neutrophils, which was not apparent with CF-DA.

\section{Susceptibility of Cellular Esterases to Heat Treatment}

To determine if the fluorescence generated by cells was due to enzymatic hydrolysis of DCFH-DA, mononuclear cells were sonicated. An aliquot was heated at $100^{\circ} \mathrm{C}$ for

TABLE 1. Percentage of Baseline Fluorescence After Addition of NaOH*

\begin{tabular}{lcr}
\hline & Mononuclear cells & \multicolumn{1}{c}{ Neutrophils } \\
\hline Whole cells & $362 \pm 134$ & $75.5 \pm 15.4$ \\
Sonicates & $586 \pm 235$ & $106.7 \pm 44.9$ \\
\hline
\end{tabular}

aData (mean $\pm \mathrm{SD}, \mathrm{N}=4$ ) showing the percentage increase over baseline fluorescence for both mononuclear cells and neutrophils after addition of $0.1 \mathrm{~N} \mathrm{NaOH}$ and neutralizing the $\mathrm{pH}$ before measurement of fluorescence as described in Materials and Methods.

TABLE 2. Percentage of Probe Not Hydrolyzed by Mononuclear Cells

\begin{tabular}{|c|c|c|}
\hline & Sonicates & Whole cells \\
\hline $\begin{array}{l}\text { DCFH-DA } \\
\text { CF-DA }\end{array}$ & $\begin{array}{l}85.2 \pm 20.3 \\
10.35 \pm 4.8\end{array}$ & $\begin{array}{l}58.8 \pm 12.7 \\
28.6 \pm 10.5\end{array}$ \\
\hline
\end{tabular}

${ }^{a}$ Table 2 shows data (mean $\pm S D, N=4$ ) indicating the amount of probe (DCFH-DA or CF-DA) not hydrolyzed by either the sonicates or whole cells in the absence of added $\mathrm{NaOH}$ hydrolysis. Whole cell fluorescence was corrected for background fluorescence in the absence of added $\mathrm{H}_{2} \mathrm{O}_{2}$. Measurements were made spectrofluorometrically with excitation at $488 \mathrm{~nm}$ and emission at $525 \mathrm{~nm}$. 
$5 \mathrm{~min}$ to destroy enzymatic activity and $5 \mu \mathrm{M}$ DCFHDA was added to heated and unheated sonicates, and incubated for $15 \mathrm{~min}$ at $37^{\circ} \mathrm{C}$. The fluorescence in the heated sonicates, owing mainly to basal oxidant activity, was less than half that of the untreated samples. Addition of $\mathrm{H}_{2} \mathrm{O}_{2}$ increased the fluorescence of the heated sonicates by 2.7 -fold, while the unheated sonicate's fluorescence increased 6.3-fold. Similar values were observed for neutrophils, demonstrating that DCFH-DA hydrolysis in both these cell types is primarily enzymatic.

\section{Comparison Between PMA Stimulation and $\mathrm{H}_{2} \mathrm{O}_{2}$ Oxidation}

To determine the degree of hydrolysis of the DCFHDA in mononuclear cells and neutrophils, $1.5 \times 10^{6}$ monocytes (approximately $4.5 \times 10^{6}$ mononuclear cells) or neutrophils were loaded with DCFH-DA $(5 \mu \mathrm{M})$ for 15 min at $37^{\circ} \mathrm{C}$. After washing, each cell suspension was divided into two equal portions, and one was stimulated with PMA (100 ng/ml) for $15 \mathrm{~min}$ at $37^{\circ} \mathrm{C}$, while PBS was added to the other. Bulk fluorescence was measured spectrofluorometrically as previously described. The PMA-stimulated samples of both cell types increased in fluorescence intensity, indicating oxidation of fluorochromes as a result of cell activation. However, the increase was markedly less in mononuclear cells than in neutrophils (Fig. 2).

To determine whether further oxidation could occur if excess oxidant $\left(\mathrm{H}_{2} \mathrm{O}_{2}\right)$ was added to these PMA-stimulated samples, $1 \mathrm{mM} \mathrm{H}_{2} \mathrm{O}_{2}$ was added to each sample and the spectrofluorometric measurements repeated. The addition of $\mathrm{H}_{2} \mathrm{O}_{2}$ to DCFH-DA-loaded cells should oxidize intracellular DCFH to the fluorescent product DCF. In resting cell preparations (which are loaded with DCFHDA), the addition of $\mathrm{H}_{2} \mathrm{O}_{2}$ should produce a response similar to that of PMA stimulation. Fluorescence of both cell types increased after addition of $\mathrm{H}_{2} \mathrm{O}_{2}$. Each measurement was made 7 min after addition of $\mathrm{H}_{2} \mathrm{O}_{2}$. The results indicated that both PMA and $\mathrm{H}_{2} \mathrm{O}_{2}$ were capable of causing cellular fluorescence, but that the PMA-stimulated cells were consistently more fluorescent than in cells which the fluorescence was produced by $\mathrm{H}_{2} \mathrm{O}_{2}$ oxidation of the intracellular DCFH (Table 3). Mononuclear cells again produced markedly less fluorescence than did neutrophils treated identically with $\mathrm{H}_{2} \mathrm{O}_{2}$. These results again confirmed deficient hydrolysis of DCFH-DA in the mononuclear cells. We then examined whether the introduction of DCFH-DA in a different manner would affect hydrolysis and oxidation.

\section{Measurement of DCFH-DA in Phagocytosing Mononuclear Cells}

To determine whether intracellular fluorescence could be measured if DCFH-DA were introduced inside bacte-
TABLE 3. Percentage Increase in Fluorescence After Addition of $1 \mathrm{mM} \mathrm{H}_{2} \mathrm{O}_{2}$ "

\begin{tabular}{llc}
\hline & Monocytes & Neutrophils \\
\hline Unstimulated & $287.3 \pm 45.5$ & $830.7 \pm 70.9$ \\
Stimulated & $176 \pm 23.3$ & $154.2 \pm 21.6$ \\
\hline
\end{tabular}

a'Whole cells (neutrophils or mononuclear cells) were loaded with DCFH-DA $(5 \mu \mathrm{M})$. One portion of each cell type was stimulated with PMA (100 $\mathrm{ng} / \mathrm{ml})$ and the other was left unstimulated. Spectrofluorometric measurements were made on each sample. Immediately, $\mathrm{H}_{2} \mathrm{O}_{2}(1 \mathrm{mM})$ was added to each tube and spectrofluorometric measurements repeated after $7 \mathrm{~min}$. Results indicate that both mononuclear cells and neutrophil intracellular DCFH can be oxidized by either cell activation (PMA) or exogenous oxidant $\left(\mathrm{H}_{2} \mathrm{O}_{2}\right)$. Monocyte whole cell absolute fluorescence per cell was considerably less than neutrophil whole cell fluorescence. Data represent means $\pm S D, N=4$.

ria, the following experiment was undertaken. Staphylococcus aureus $\left(1 \times 10^{9} / \mathrm{ml}\right)$ were preloaded by incubation with DCFH-DA $(5 \mu \mathrm{M})$ for $15 \mathrm{~min}$ at $37^{\circ} \mathrm{C}$ in PBS-gel. Bacteria were extensively washed in PBS-gel (4 times at $10,000 \mathrm{~g}$ for $3 \mathrm{~min}$ ) and opsonized with pooled human serum for $30 \mathrm{~min}$ at $37^{\circ} \mathrm{C}$. After washing, S. aureus were added to mononuclear cells which had not been loaded with DCFH-DA. DCFH-DA-loaded S. aureus alone were not fluorescent by flow cytometry and neither were mononuclear cells fluorescent in the absence of $S$. aureus. Flow cytometric fluorescence measurements were then made on the light-scatter-gated mononuclear cells population over $15 \mathrm{~min}$, during which the bacteria were being phagocytozed. A steady increase in mononuclear-cells-associated fluorescence was observed during this time (Fig. 3). The cells were also observed by fluorescence microscopy. Mononuclear cells exposed to DCFH-DA-loaded bacteria contained many diffusely fluorescent granules, while no free bacteria were fluorescent. This suggests that monocytes were able to oxidize intrabacterial DCFH, depsite their inability to oxidize intracellular (monocyte) DCFH.

\section{DISCUSSION}

A preliminary report by Bender et al. [4] has indicated that monocytes produce fluorescent products from the intracellular fluorochrome DCFH-DA, in a similar manner to neutrophils [3]. We have extended these studies by examining the oxidative metabolism of the human mononuclear cells using this fluorochrome by both spectrofluorometric and flow cytometric studies.

We have used the fluorochrome DCFH-DA, which is hydrolyzed intracellularly to nonfluorescent DCFH in neutrophils. During the oxidative burst, DCFH is converted into fluorescent DCF which can be quantified by flow cytometry. When mononuclear cells were isolated, 


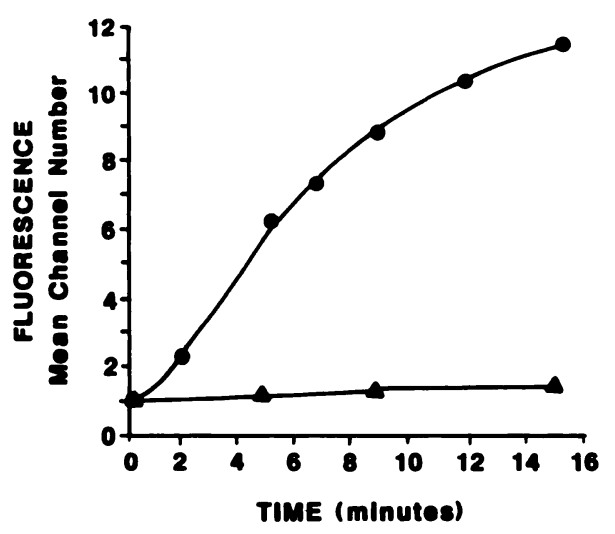

Fig. 3. Plot of mean fluorescence channel number standardized 20 that background filuorescence is channel 1. This figure shows the increase in mean fluorescence channel No. in monocytes (which did not contain DCFH-DA) after stimulation with preopsonized DCFH-DA-loaded S. aureus. A rapid increase in fluorescence was observed as monocytes phagocytosed the $S$. aureus. Almost no increase in fluorescence could be detected in DCFH-DA-loaded monocytes stimulated with PMA. -O S. aureus loaded with DCFH-DA plus unloaded monocytes; $\Delta-\Delta$ monocytes alone (unloaded).

loaded with DCFH-DA and stimulated with PMA, no or minimal fluorescence was observed within the monocytes using flow cytometric methods.

To test the possibiliy that the lack of fluorescence may have been related to the isolation procedure, unseparated leukocytes from whole blood were also evaluated in this assay. DCF fluorescence of monocytes, lymphocytes, and neutrophils was measured by simultaneously gating each population based on light-scatter properties. The neutrophils always responded with a rapid increase in DCF fluorescence, whereas the lymphocytes and monocytes remained nonfluorescent. The lack of fluorescence, therefore, appeared to be unrelated to the technical procedures of cell isolation and preparation for assay. Thus, mononuclear cells appear to be incapable of forming intracellular DCF fluorescence in significant amounts after stimulation with PMA.

Ample evidence exists that stimulated monocytes produce oxygen radicals [8-11,13]. Although we were unable to measure intracellular fluorescence by flow cytometry, we were able to measure spectrophotometrically an increase in whole cell bulk fluorescence (Fig. 2) and $\mathrm{O}_{2}{ }^{-}$ production by measuring superoxide dismutase (SOD) inhibitable cytochrome $\mathrm{C}$ reduction (data not presented) after PMA stimulation.

The source of this extracellular DCF is unknown, but several possibilities exist. The extracellular DCF could have been formed either intracellularly, or in the monocyte plasma membrane and subsequently released from the cell, although this is less likely due to the polar nature of DCF. Alternatively, secreted oxygen metabolites may have converted any extracellular DCFH to DCF. To discriminate between these hypotheses, bacteria loaded with DCFH-DA were phagocytosed by monocytes and the resultant intracellular fluorescence measured by flow cytometry. After phagocytosis had occurred, the fluorescence inside the monocytes had increased in a similar manner (although not to the same extent) as that observed with PMA stimulation of DCFH-DA-loaded neutrophils. Free, extracellular bacteria remained nonfluorescent, suggesting that the bacteria-related DCF was formed by $\mathrm{H}_{2} \mathrm{O}_{2}$ generated intracellularly by the monocytes. The possibility exists that the $\mathrm{H}_{2} \mathrm{O}_{2}$ could have been formed by lysosomes or in the plasma membrane of the monocytes. The former seems likely in view of the lack of fluorescence generated in DCFH-DA-loaded PMA stimulated monocytes. Also, under fluorescence microscopy, the fluorescence was observed as a diffuse cytoplasmic glow within the monocytes. This is further strengthened by the fact that DCFH-DA-related fluorescence is not measurable in alveolar and peritoneal macrophages after stimulation with PMA or IgG or IgA immune complexes (Robinson et al., manuscript in preparation). Our findings support the concept of $\mathrm{H}_{2} \mathrm{O}_{2}$ release into the phagosome after phagocytosis, leading to the possibility that DCFH may be either leaking from DCFH-DA-loaded monocytes or formed on the plasma membrane after stimulation with nonparticular substances.

There are a number of other explanations as to why little DCF-related fluorescence was observed with nonparticulate stimuli. One might be that esterases necessary for the hydrolysis of DCFH-DA were either lacking or partitioned in such a way as to be unavailable. A similar fluorochrome, CF-DA, which fluoresces immediately upon hydrolysis, was used to test for esterase availability. No difference was observed in the final fluorescence of either mononuclear cells or neutrophils with this dye, suggesting that the esterases were indeed available. Our studies with addition of $\mathrm{NaOH}$ to hydrolyze DCFH-DA did indicate that with mononuclear cells, further hydrolysis was possible, suggesting that sufficient DCFH-DA was taken up by the mononuclear cells. This was particularly evident with the monocyte sonicates where significantly more hydrolysis was possible compared with the neutrophil sonicates. In this case, where DCFH-DA was added to the sonicates of mononuclear cells, a greater percentage increase in fluorescent product could be achieved than from the neutrophil treated in a similar manner. Despite this finding, it would not be sufficient to account for the lack of fluorescence observed within whole cells.

Our studies utilizing CF-DA demonstrated that both mononuclear cells and neutrophils were capable of hydrolyzing the CF-DA directly to the fluorescent carboxy- 
fluorescin. There does appear to be some difference between the way the mononuclear cells hydrolyze DCFHDA and CF-DA. Both cell types rapidly form the fluorescent product carboxyfluorescin, indicating the presence of esterases for hydrolysis; however, the reasons for the different hydrolytic activity with DCFH-DA are not clear. Despite this, there are sufficient esterases present in the mononuclear cells for the formation of some DCFH. In DCFH-DA-loaded monocytes, DCFH equilibrates within the hydrophobic-lipid-containing areas of the plasma membrane. During PMA stimulation a considerable proportion of the $\mathrm{H}_{2} \mathrm{O}_{2}$ or $\mathrm{O}_{2}{ }^{-}$is generated extracellularly, where the DCF so formed would be unavailable for flow cytometric determination.

We conclude that there are significant differences in the oxidative mechanisms of neutrophils and monocytes not previously observed. It appears that in response to soluble stimuli which are not internalized by phagocytic mechanisms, monocytes mainly secrete their oxygen metabolites, whereas such metabolites are also formed within neutrophils. These data also suggest that there may be incomplete intracellular hydrolysis of DCFH-DA, probably as a result of esterase compartmentalization and thus unavailability. Further, since stimulated cells release esterases and peroxidases owing to degranulation, it is likely that extracellular hydrolysis of DCFH-DA could occur. The DCFH so formed could then be converted by $\mathrm{H}_{2} \mathrm{O}_{2}$ in the presence of peroxidase to the fluorescent DCF, extracellularly. During phagocytosis cytotoxic oxygen species are released into bacterial-containing phagosomes of both neutrophils and monocytes, allowing the measurement of the intracellularly formed fluorescence. The exact mechanisms of these interactions is yet to be determined; however, it appears likely that the lysosomal enzymes and peroxidase inside the phagolysosome penetrate the bacteria, converting the DCFH to DCF. The extracellular bacteria remain nonfluorescent because of the inability of extracellular peroxidase to penetrate the bacteria.

\section{ACKNOWLEDGMENTS}

Portions of this work were supported by NIH grants GM-38827, HL-28737, and HL-31963, a grant in aid from the American Heart Association and its Michigan
Affiliate, and funding from the EPICS and Diagnostics Divisions of Coulter Electronics. Dr. Phan is an Established Investigator of the American Heart Association.

\section{REFERENCES}

1. Babior, B.M., Kipnes, R.S., and Curnutte, J.T. Biological defence mechanisms. The production by leukocytes of superoxide, a potential bactericidal agent. J. Clin. Invest. 52, 741, 1973.

2. Bass, D.A. Olbrantz, P., Szejda, P., Seeds, M.C., and McCall, C.E. Subpopulations of neutrophils with increased oxidative product formation in blood of patients with infection. J. Immunol. 136, 860, 1986.

3. Bass, D.A. Parce, J.W., DeChatelet, L.R. Szejda, P., Seeds, M.C., and Thomas M. Flow cytometric studies of oxidative product formation by neutrophils: A graded response to membrane stimulation. J. Immunol. 130, 1910, 1983.

4. Bender, J.G., Van Epps, D.E., and Steinkamp, J.A. Characterization of human mononuclear cells using reduced pyridine nucleotide fluorescence and flow cytometry. J. Leukocyte Biol. 38, 603, 1985.

5. Boyum, A. Isolation of mononuclear cells and granulocytes from human blood. Scand. J. Clin. Lab. Invest. 21(Suppl. 97), 77, 1968.

6. Duque, R.E., Phan, S.H., Hudson, J.L., Till, G.O., and Ward, P.A. Functional defects in phagocytic cells following thermal injury. Application of flow cytometric analysis. Am. J. Pathol. 118, 116, 1985.

7. Johnston, R.B., Lehmeyer, J.E., and Guthrie, L.A. Generation of superoxide anion and chemiluminescence by human monocytes during phagocytosis and on contact with surface-bound immunoglobulin g. J. Exp. Med. 143, 1551, 1976.

8. Lampert, M.B., and Weiss, S.J. The chlorinating potential of the human monocyte. Blood 62, 645, 1983.

9. Locksley, R.M., Wilson, C.B., and Klebanoff, S.J. Increased respiratory burst in myeloperoxidase-deficient monocytes. Blood 62, 902, 1983.

10. Musson, R.A., McPhail, L.C. Shafran, H., and Johnston, R.B. Differences in the ability of human peripheral blood monocytes and in vitro monocyte-derived macrophages to produce superoxide anion: Studies with cells from normals and patients with chronic granulomatous disease. J. Reticuloendothel. Soc. 31, 261, 1982.

11. Nakagawara, A., Nathan, C.F., and Cohn, Z.A. Hydrogen peroxide metabolism in human monocytes during differentiation in vitro. J. Clin. Invest. 68, 1243, 1981.

12. Nelson, R.D., Mills, E.L., Simmons, R.L., and Quie, P.G. Chemiluminescence response of phagocytizing human monocytes. Infect. Immun. 14, 129, 1976.

13. Reiss, M., and Roos, D. Differences in oxygen metabolism of phagocytosing monocytes and neutrophils. J. Clin. Invest. 61, $480,1978$.

14. Robinson, J. Paul, Wakefield, D., Graham, D.M., Easter, J.F., and Penny, $R$. The chemiluminescent response of normal human leukocytes to Chlamydia trachomatis. Diagn. Immunol. 3, 119, 1985. 